\title{
Is soy intake related to age at onset of menarche? A cross-sectional study among adolescents with a wide range of soy food consumption
}

\author{
Gina Segovia-Siapco ${ }^{1 *}$, Peter Pribis $^{3}$, Mark Messina $^{4}$, Keiji Oda $^{2}$ and Joan Sabaté ${ }^{1,2}$
}

\begin{abstract}
Background: Early onset of menarche may negatively influence the future health of adolescent girls. Several factors affect the timing of menarche but it is not clear if soy foods consumption around pubertal years plays a role; thus, we examined its relation to age at onset of menarche (AOM) in a high soy-consuming population.

Methods: We conducted a cross-sectional study on 339 girls ages 12-18 years attending middle and high schools near two Seventh-day Adventist universities in California and Michigan using a web-based dietary questionnaire and physical development tool. Soy consumption (categorized as total soy, meat alternatives, tofu/traditional soy, and soy beverages) was estimated from the questionnaire, while AOM was self-reported. Data analyses included descriptive statistics, Cox proportional hazards ratios, Kaplan-Meier curves and Poisson regression with adjustment for relevant confounders.
\end{abstract}

Results: Mean (SD) intakes were: total soy,12.9 (14.4) servings/week; meat alternatives, 7.0 (8.9) servings/week; tofu/ traditional soy foods, 2.1 (3.8) servings/week; soy beverages, 3.8 (6.3) servings/week. Mean AOM was 12.5 (1.4) y for those who reached menarche. Consumption of total soy and the 3 types of soy foods was not significantly associated with $\mathrm{AOM}$ and with the odds for early- or late-AOM. Adjustment for demographic and dietary factors did not change the results.

Conclusion: Soy intake is not associated with AOM in a population of adolescent girls who have a wide range of, and relatively higher, soy intake than the general US population. Our finding suggests that the increasing popularity of soy in the US may not be associated with AOM.

Keywords: Soy, Adolescence, Age at menarche, Pubertal timing, Puberty, Seventh-day Adventists

\section{Background}

For the past four decades, age at which puberty occurs among girls-manifested as breast development, appearance of pubic hair, and onset of menarche-has been commencing earlier. Although evidence points to nonlinear variability in menarcheal age from decade to decade [1], the mean age at onset of menarche $(\mathrm{AOM})$ in the United States decreased by an average of 3 to $5 \frac{1}{2}$ months from 1960 to 1990 [2]. Breast development, typically considered an earlier manifestation of puberty compared to menarche, is also commencing at a younger age [3]. The secular trends in pubertal development raise concerns

\footnotetext{
* Correspondence: gsiapco@llu.edu

'Department of Nutrition, Loma Linda University, 24951 North Circle Dr.

Nichol Hall 1105, Loma Linda, CA 92350, USA

Full list of author information is available at the end of the article
}

because early onset of puberty may negatively influence the future health of adolescent girls [4]. Earlier menarche has been implicated in the etiology of breast and ovarian cancer $[5,6]$; in fact, early menarche has been found to contribute more to breast cancer risk than late menopause [7]. Therefore, the decline in age at which menarche occurs may result in an increased incidence of hormone-related cancers.

Several investigations have focused on the role of genetics $[8,9]$, early life exposure to environmental factors and xenobiotics [10-12], and body composition/weight status [13-16] on pubertal development. Certain dietary factors, such as animal protein and meat $[17,18]$ and milk and total dairy [19], have also been linked to pubertal timing. Over the past two decades, foods made from soybeans 
have increased in popularity in many western countries due in part to awareness of the proposed health benefits of these foods. Soy foods are sources of high-quality protein, substantial amounts of essential fatty acids, isoflavones, and in some cases, dietary fiber. Isoflavones bind to estrogen receptors and exert estrogen-like effects under certain conditions [20], thus, isoflavone exposure may affect sexual maturation of children [21]. It is, therefore, not surprising that some studies investigating pubertal development have focused on soy isoflavones.

The few investigations on the effects of exposure to soy early in life on the onset of menarche have produced mixed results [22-24]. Given the possible hormonal effects of soy and the decline in age at onset of puberty in the US - although this decline has also occurred in countries not exposed to soy - there is clearly a need for additional soy and isoflavone research in this area. However, isoflavones are only one of the many components of soy that may also be associated with pubertal timing. Evidence suggests that vegetable and animal protein may have differential effects on pubertal development [25-27]. In addition, dietary fiber and fat have been found to influence the menarcheal age [28-30]. Thus, the possible synergism among soy components and their cumulative effect on pubertal development needs to be considered.

The Adventist population offers an opportunity to study the relationships between intake of soy foods and AOM because a high percentage of them are vegetarians and include soy-containing foods in their diet. In fact, our preliminary data (unpublished) from a pilot study among adolescents attending Adventist schools or public schools near major Adventist universities in Southern California and Michigan, revealed a wide range in the consumption of soy-containing foods. Therefore, our aim was to determine if soy intake is associated with the AOM in a population that is known to have extensive exposure to soy.

\section{Methods}

\section{Study design and participants}

The Teen Food and Development Study is a cross-sectional study conducted using a web-based survey to determine the relationships between food intake and pubertal development. In particular, we sought to determine how soy consumption is related to the AOM. The study participants were recruited from Adventist and public middle and high schools near major Adventist universities in southern California and Michigan. Parents and prospective participants enrolled online through a website that was designed specifically for the study. Parental permission was granted by filling out the online informed consent form together with the child who also filled out the form. To ascertain that the parent indeed approved the child's participation, a confirmation call to the parent was made. The online mode of collecting informed consent by the parents, assent of the potential participant, and all study protocols were approved by the Institutional Review Boards of Loma Linda University and Andrews University.

Assuming a unidirectional relationship between soy consumption and AOM, we determined a priori that a sample size of 340 will yield $75 \%$ power to detect a 3-month difference in AOM between consumers and non-consumers of soy. Adolescent girls 12 to 18 years old were included in the study. We limited the study population to this age range because of the likelihood that they have already reached menarche and to cover a wider range of ages at which menarche might occur. Menarche is considered as a late manifestation of puberty compared to thelarche and pubarche [31], but since menarche is regarded as an important event in the life of a teenage girl, this pubertal marker is most accurately remembered [32]. A total of 339 girls completed the survey. Twelve were not included in the analysis: 9 have missing data on AOM and 3 had very high and/or improbable values for intake of soy foods and total food intake. Thus, 327 adolescent girls with complete information on soy intake and AOM were considered eligible for this study.

\section{Assessment and validation of soy consumption}

The self-administered web-based survey-which was pretested on a representative group $(n=18)$ of adolescent girls of the same age for clarity, comprehension, and relevance-included a semi-quantitative food frequency questionnaire (FFQ) composed of 151 food items (see Additional file 1). Food items were categorized as convenience foods (32 items), protein-rich foods (29 items), starches/cereals (17 items), vegetables/fruits (21 items), dairy products (10 items), beverages (24 items), snacks/ sweets (11 items), and soups/legumes (7 items). Participants were asked to self-report frequency of their intake during the previous 6 months. Frequency of intake categories were: never/rarely, 1-3 times per month, once per week, 2-4 times per week, 5-6 times per week, once per day, 2-3 times per day, and $\geq 4$ times per day. The FFQ had 36 soy-containing foods, most of which are meat or dairy substitutes. Soy foods were grouped into three categories: meat alternatives, tofu/traditional soy, and soy beverages/ dairy substitutes.

Soy consumption using the web-based FFQ was validated relative to 6 food records which were provided by each of a subgroup of participants $(n=70)$ from both study sites. Corrected correlation coefficient for intake of soy-containing foods was 0.63 (95\% bootstrap BCa CI: $0.43,0.77)$. Total agreement (+/ 1 quartile) between the two methods was $83 \%$ while gross misclassification was $2.9 \%$. Thus, we considered the web-based FFQ to provide a valid estimate of soy foods consumption and in ranking individuals according to their intake. 


\section{Assessment of AOM}

The web-based survey included questions on physical and pubertal development. The AOM was self-reported by answering the question, "What was your age when you had your first-ever period?" where participants were asked to report their age in years to the nearest number of months (e.g., 11 years and 9 months). At the time of the survey, 293 participants reported that they were already menstruating while $34(\sim 10 \%)$ had not yet menstruated.

\section{Data management and analysis}

Descriptive analysis was performed for the demographic profile of the participants. Tests to compare distributions and means or medians (i.e., $\chi^{2}, t$-test, one-way ANOVA, and Kruskal-Wallis test) among the soy intake categories were performed testing at $\alpha=0.05$. Since some of the participants had not yet reached menarche $(\sim 10 \%)$, we did time-to-event analyses to determine differences in AOM among the different consumption levels of total soy, meat alternatives, tofu/ traditional soy, and soy beverages/dairy substitutes. Cox proportional hazards regression/modeling was performed to estimate the hazard of reaching menarche at any given age using both continuous and categorical levels of soy exposure. Kaplan-Meier curves were plotted to check if there were observable differences in the timing of AOM between low- (below median of total soy consumption) and high- (above median of total soy consumption) soy consumers using crude energy-adjusted total soy intake. In addition, we conducted modified Poisson regression modeling to estimate the relative risk for early and late menarche among the levels of soy consumption groups. Early-onset menarche was defined as $\mathrm{AOM}<12.0$ years and late-onset menarche as $\mathrm{AOM} \geq$ 14.0 years which roughly coincided with the $25^{\text {th }}$ and $75^{\text {th }}$ percentiles, respectively, of the AOM distribution of the study participants. The $25^{\text {th }}$ and $75^{\text {th }}$ percentiles have been used as cut-points in other studies to define the timing of menarche [33].

Soy consumption was measured as frequency and as servings of soy foods and total food intake was expressed as the number of servings of all foods consumed per day. A crude adjustment for energy intake was done by dividing the number of servings of soy by the number of servings of total food intake. From the adjusted values, quartiles of total soy and meat alternatives consumption were compared using the lowest quartile group (Quartile $1)$ as the reference. Due to more skewed energy-adjusted intake distributions of tofu/traditional soy and soy beverages/dairy substitutes, levels of intake were divided into non-consumers ("0" soy consumption), low-to-moderate consumers ( $\leq 75$ th percentile but excluding non-consumers) and high consumers $\left(>75^{\text {th }}\right.$ percentile); non-consumers was used as the reference.
Models were adjusted for covariates which were significantly distributed differently among the levels of soy consumption groups - age, study site, type of school, socio-economic status (measured in terms of mother's and father's educational levels), ethnicity (measured in terms of mother's and father's ethnicities) - and those purported to be associated with age of menarche, such as meat and total food intake, or mediate the association between food intake and AOM, such as body mass index z-score (BMIz). An interaction term between soy intake and BMIz was initially included in all models and found not significant, thus, was excluded from the final model. All analyses were performed using SAS 9.3 (SAS Institute Inc., Cary, NC, USA) at an alpha level of 0.05 .

\section{Results}

Table 1 presents the participants' characteristics according to their soy intake categories. Age distributions and mean ages were similar across soy consumption levels. Of the 327 participants, 46.5 and $53.5 \%$ were from Michigan and California, respectively. Most study participants have highly educated parents, the majority of whom (about $80 \%$ ) had at least a four-year college degree. More than $40 \%$ of the parents were Caucasian while Hispanics, Blacks, Asians, and other ethnicities accounted for $18-20 \%, 10-12 \%, 14-15 \%$, and $11 \%$, respectively. There were statistically significant distribution differences across the levels of soy consumption in terms of site, type of school, mother's and father's education, and mother's and father's ethnicities. Approximately $24 \%$ of the participants never or rarely eat meat, and meat intake significantly differed across soy intake groups $(\mathrm{p}<0.0001)$. In contrast, $\mathrm{BMI}$ and BMIz did not differ significantly across the soy consumption categories. Distribution of AOM and the unadjusted mean $\mathrm{AOM}$ of those who have reached menarche (overall, $12.5 \pm 1.4$ y) did not significantly differ across levels of soy consumption. Similar non-significant differences were also found for meat alternatives, tofu/traditional soy, and soy beverages/dairy substitutes (not shown).

More than half of the participants (55\%) eat soy foods more than once a day (Table 2). Fifty-four percent eat meat alternatives more than 4 times per week. While $23 \%$ eat tofu and other traditional soy foods 3 or more times per week, $45 \%$ never or rarely eat them. Similarly, $22 \%$ drink soy beverages once or more per day while $39 \%$ never or rarely do. Meat alternatives comprise most of the weekly soy foods consumed by the participants (mean $[\mathrm{SD}]=7.0[8.9] \mathrm{svg} / \mathrm{wk}$ ) while soy beverages and tofu/traditional soy foods are eaten in lesser quantities, 3.8 (6.3) vs. 2.1 (3.8) svg/wk, respectively.

Results of the Cox proportional hazards regression for the occurrence of menarche according to consumption of total soy and the 3 types of soy foods at both the continuous and categorical levels are presented in 
Table 1 Demographic characteristics of participants as a whole and according to categories of total soy consumption level

\begin{tabular}{|c|c|c|c|c|c|c|}
\hline & Total $(n=327)$ & Lev & vel of soy consumptior & n (frequency of intak & & p-value \\
\hline & & $\begin{array}{c}\leq 1 \times / \text { week }(n=62) \\
\text { count }(\%)\end{array}$ & $\begin{array}{c}>1 \times / \text { week }-\leq 1 \times / \text { day } \\
(n=85) \text { count }(\%)\end{array}$ & $\begin{array}{l}>1 \times / \text { day }-\leq 3 \times / \text { day } \\
(n=111) \text { count }(\%)\end{array}$ & $\begin{array}{c}>3 \times / \text { day }(n=69) \\
\text { count }(\%)\end{array}$ & \\
\hline Age, years & & & & & & $0.574^{b}$ \\
\hline 12 & $26(8.0 \%)$ & $6(9.7 \%)$ & $7(8.2 \%)$ & $9(8.1 \%)$ & $4(5.8 \%)$ & \\
\hline 13 & $51(15.6 \%)$ & $8(12.9 \%)$ & $13(15.3 \%)$ & $19(17.1 \%)$ & $11(15.9 \%)$ & \\
\hline 14 & $56(17.1 \%)$ & $9(14.5 \%)$ & $17(20.0 \%)$ & 19 (17.1\%) & $11(15.9 \%)$ & \\
\hline 15 & $61(18.7 \%)$ & $7(11.3 \%)$ & $18(21.2 \%)$ & 19 (17.1\%) & 17 (24.6\%) & \\
\hline 16 & 59 (18.0\%) & $14(22.6 \%)$ & $8(9.4 \%)$ & $21(18.9 \%)$ & $16(23.2 \%)$ & \\
\hline 17 & $50(15.3 \%)$ & $14(22.6 \%)$ & $15(17.6 \%)$ & $14(12.6 \%)$ & $7(10.1 \%)$ & \\
\hline 18 & $24(7.3 \%)$ & $4(6.5 \%)$ & $7(8.2 \%)$ & $10(9.0 \%)$ & $3(4.3 \%)$ & \\
\hline Mean age (SD), years & $15.0(1.5)$ & $15.2(1.8)$ & $14.9(1.8)$ & $14.9(1.8) 1$ & $14.9(1.5)$ & $0.771^{\mathrm{C}}$ \\
\hline Site & & & & & & $0.006^{b}$ \\
\hline Michigan & $152(46.5 \%)$ & $41(66.1 \%)$ & $36(42.4 \%)$ & $49(44.1 \%)$ & $26(37.7 \%)$ & \\
\hline California & $175(53.5 \%)$ & $21(33.9 \%)$ & 49 (57.6\%) & $62(55.9 \%)$ & $43(62.3 \%)$ & \\
\hline School & & & & & & $<.0001^{\mathrm{b}}$ \\
\hline Public & $38(11.6 \%)$ & $23(37.1 \%)$ & $8(9.4 \%)$ & $4(3.6 \%)$ & $3(4.3 \%)$ & \\
\hline Private & $289(88.4 \%)$ & 39 (62.9\%) & 77 (90.6\%) & $107(96.4 \%)$ & $66(95.7 \%)$ & \\
\hline Mother's education & & & & & & $0.0008^{b}$ \\
\hline High school level/graduate & $63(19.3 \%)$ & $24(38.7 \%)$ & $13(15.3 \%)$ & $13(11.7 \%)$ & $13(18.8 \%)$ & \\
\hline College level/degree & $133(40.7 \%)$ & $26(41.9 \%)$ & $41(48.2 \%)$ & $50(45.0 \%)$ & $30(43.5 \%)$ & \\
\hline Masters/Doctoral level/degree & $131(40.1 \%)$ & $12(19.4 \%)$ & $31(36.5 \%)$ & $48(43.2 \%)$ & $26(37.7 \%)$ & \\
\hline Father's education & & & & & & $0.0001^{b}$ \\
\hline High school level/graduate & $68(20.8 \%)$ & $24(38.7 \%)$ & $21(24.7 \%)$ & $13(11.7 \%)$ & $10(14.5 \%)$ & \\
\hline College level/degree & $113(34.6 \%)$ & $28(45.2 \%)$ & $35(41.2 \%)$ & $43(38.7 \%)$ & $21(30.4 \%)$ & \\
\hline Masters/Doctoral level/degree & $146(44.6 \%)$ & $10(16.1 \%)$ & $29(34.1 \%)$ & $55(49.5 \%)$ & $38(55.1 \%)$ & \\
\hline Mother's ethnicity & & & & & & $0.0004^{b}$ \\
\hline White & $142(43.4 \%)$ & $35(56.5 \%)$ & $34(40.0 \%)$ & $52(46.8 \%)$ & $21(30.4 \%)$ & \\
\hline Black & $34(10.4 \%)$ & $3(4.8 \%)$ & $10(11.8 \%)$ & $13(11.7 \%)$ & $8(11.6 \%)$ & \\
\hline Hispanic & $65(19.9 \%)$ & $15(24.2 \%)$ & $15(17.6 \%)$ & $16(14.4 \%)$ & $19(27.5 \%)$ & \\
\hline Asian & $50(15.3 \%)$ & $3(4.8 \%)$ & $8(9.4 \%)$ & $22(19.8 \%)$ & $17(24.6 \%)$ & \\
\hline Other & $36(11.0 \%)$ & $6(9.7 \%)$ & $18(21.2 \%)$ & $8(7.2 \%)$ & $4(5.8 \%)$ & \\
\hline Father's ethnicity & & & & & & $0.004^{b}$ \\
\hline White & $144(44.0 \%)$ & $36(58.1 \%)$ & $31(36.5 \%)$ & $53(47.7 \%)$ & $24(34.8 \%)$ & \\
\hline Black & $41(12.5 \%)$ & $4(6.5 \%)$ & $14(16.5 \%)$ & $15(13.5 \%)$ & $8(11.6 \%)$ & \\
\hline Hispanic & $60(18.3 \%)$ & $12(19.4 \%)$ & $15(17.6 \%)$ & $16(14.4 \%)$ & $17(24.6 \%)$ & \\
\hline Asian & $46(14.1 \%)$ & $2(3.2 \%)$ & $9(10.6 \%)$ & $20(18.0 \%)$ & $15(21.7 \%)$ & \\
\hline Other & $36(11.0 \%)$ & $8(12.9 \%)$ & $16(18.8 \%)$ & $7(6.3 \%)$ & $5(7.2 \%)$ & \\
\hline Meat intake, frequency/week & & & & & & $<.0001^{\mathrm{b}}$ \\
\hline Never & $79(24.2 \%)$ & $0(0.0 \%)$ & $8(9.4 \%)$ & $40(36.0 \%)$ & $31(44.9 \%)$ & \\
\hline$\leq 1 x /$ day & $111(33.9 \%)$ & $17(27.4 \%)$ & $38(44.7 \%)$ & $39(35.1 \%)$ & $17(24.6 \%)$ & \\
\hline$>1 x /$ day & $137(41.9 \%)$ & $45(72.6 \%)$ & $39(45.9 \%)$ & $32(28.8 \%)$ & $21(30.4 \%)$ & \\
\hline Median meat intake (IQR), svg/d & $5.5(12.5)$ & $13.3(12.5)$ & $7.0(8.0)$ & $2.0(8.0)$ & $1.5(10.0)$ & $<.0001^{\mathrm{d}}$ \\
\hline Median BMI (IQR), kg/m² & $21.9(4.2)$ & $22.3(3.7)$ & $22.7(4.7)$ & $21.3(4.1)$ & $21.5(3.8)$ & $0.088^{\mathrm{d}}$ \\
\hline Mean BMI z-score (SD) & $0.43(1.02)$ & $0.57(0.92)$ & $0.62(1.14)$ & $0.28(0.98)$ & $0.34(1.01)$ & $0.084^{\mathrm{C}}$ \\
\hline
\end{tabular}




\section{Table 1 Demographic characteristics of participants as a whole and according to categories of total soy consumption level (Continued)}

\begin{tabular}{lccccc}
\hline $\begin{array}{l}\text { Age at onset of } \\
\text { menarche (AOM) }\end{array}$ & & & & \\
$\leq 9$ & $13(4.0 \%)$ & $3(4.8 \%)$ & $4(4.7 \%)$ & $4(3.6 \%)$ & $2(2.9 \%)$ \\
10 & $27(8.3 \%)$ & $6(9.7 \%)$ & $10(11.8 \%)$ & $7(6.3 \%)$ & $4(5.8 \%)$ \\
11 & $39(11.9 \%)$ & $2(3.2 \%)$ & $12(14.1 \%)$ & $13(11.7 \%)$ & $12(17.4 \%)$ \\
12 & $122(37.3 \%)$ & $30(48.4 \%)$ & $26(30.6 \%)$ & $43(38.7 \%)$ & $23(33.3 \%)$ \\
13 & $48(14.7 \%)$ & $7(11.3 \%)$ & $11(12.9 \%)$ & $19(17.1 \%)$ & $11(15.9 \%)$ \\
14 & $33(10.1 \%)$ & $5(8.1 \%)$ & $8(9.4 \%)$ & $10(9.0 \%)$ & $10(14.5 \%)$ \\
$\geq 15$ & $11(3.4 \%)$ & $2(3.2 \%)$ & $4(4.7 \%)$ & $4(3.6 \%)$ & $1(1.4 \%)$ \\
Not yet & $34(10.4 \%)$ & $7(11.3 \%)$ & $10(11.8 \%)$ & $11(9.9 \%)$ & $6(8.7 \%)$ \\
Mean AOM (SD) & $12.5(1.4)$ & $12.5(1.4)$ & $12.4(1.6)$ & $12.6(1.3)$ & $12.6(1.3)$ \\
\hline
\end{tabular}

${ }^{a}$ Excludes those who have no menarche as yet.

${ }^{\mathrm{b}}$ Chi-square test.

'One-way ANOVA.

${ }^{\mathrm{d} K r u s k a l-W a l l i s ~ t e s t . ~}$

Table 3. The risk of occurrence of menarche was not significantly related to soy food consumption. Moreover, risk did not significantly differ according to level of consumption for the 3 types of soy foods and the combined intake (total soy) when adjusted for total food intake, age, study site, type of school, mother's and father's educational levels, mother's and father's ethnicities, and meat intake. Further adjustment for BMIz did not result in substantial changes in point estimates nor significance levels; thus, only results for the model which includes BMIz was shown

\begin{tabular}{|c|c|c|c|}
\hline Frequency of intake & $\mathbf{n}$ & $\%$ & No. servings/week mean (SD) \\
\hline Total soy & & & $12.9(14.4)$ \\
\hline Up to once/week & 62 & $19.0 \%$ & \\
\hline 2-6 times/week & 85 & $26.0 \%$ & \\
\hline 1-3 times/day & 111 & $33.9 \%$ & \\
\hline 4+ times/day & 69 & $21.1 \%$ & \\
\hline Meat alternatives & & & $7.0(8.9)$ \\
\hline Less than once/week & 81 & $24.8 \%$ & \\
\hline 1-3 times/week & 70 & $21.4 \%$ & \\
\hline $4+$ times/week & 176 & $53.8 \%$ & \\
\hline Tofu/Traditional soy & & & $2.1(3.8)$ \\
\hline Never/rarely & 146 & $44.6 \%$ & \\
\hline Up to 2 times/week & 107 & $32.7 \%$ & \\
\hline 3+ times/week & 74 & $22.6 \%$ & \\
\hline Soy beverages & & & $3.8(6.3)$ \\
\hline Never/rarely & 128 & $39.1 \%$ & \\
\hline Up to once/week & 56 & $17.1 \%$ & \\
\hline 2-6 times/week & 72 & $22.0 \%$ & \\
\hline $1+/$ day & 71 & $21.7 \%$ & \\
\hline
\end{tabular}

(Table 3). The Kaplan-Meier curves (Figure 1) which plot the AOM for two energy-adjusted levels of total soy consumption show that low-consumers (median AOM=12.67 y) and high-consumers (median $\mathrm{AOM}=12.58$ y) have no significant median AOM differences.

To further determine if soy consumption groups differed in the timing of their puberty, we performed modified Poison regression. Results show that in all categories of soy foods, there were no significant linear trends in risk for either early AOM or late AOM as intake level proportionally increased (Table 4). However, when the three types of soy foods were combined (total soy), a significant early AOM risk was found among those in the second quartile (Q2) of total soy consumption (RR: 1.85 [95\% CI: $1.01,3.40], \mathrm{p}=0.047$ ) compared to the reference group, Quartile 1. No significant changes in risk for late AOM were observable even if there seems to be a decreasing risk for late menarche as soy beverage intake increases.

Certain covariates were found to be associated with AOM (not shown). BMI was consistently related to menarche (RR: 1.20 [95\% CI: 1.06, 1.35], p=0.004) and girls whose mother have a college education or higher seem to be protected from late AOM (RR: 0.37 [95\% CI: 0.16, 0.84], $\mathrm{p}=0.019$ ).

\section{Discussion}

We did not find significant associations between soy intake and $\mathrm{AOM}$ in our study population of adolescent Adventist girls who have a wide range of soy intake. The risk for an early or late AOM was not significantly different for the high versus the low soy consumers. The lack of significant associations was consistent across the different soy food types and for the combined total intake of soy foods. The biggest crude difference in the $\mathrm{AOM}$ between any soy consumption level groups in 
Table 3 Relative risks ${ }^{a}$ for the occurrence of menarche according to total soy and soy foods consumption at the continuous and categorical levels

\begin{tabular}{|c|c|c|c|c|c|c|}
\hline & \multirow[t]{2}{*}{ Continuous level ( $1 /$ day) } & \multirow[t]{2}{*}{ p-value } & \multicolumn{4}{|c|}{ Level of soy consumption ${ }^{\mathbf{b}}$} \\
\hline & & & Quartile 1 & Quartile 2 & Quartile 3 & Quartile 4 \\
\hline \multicolumn{7}{|l|}{ Total soy } \\
\hline Median intake, svg/wk & & & 0.0 & 4.5 & 13.5 & 24.2 \\
\hline Median AOM, yr ${ }^{c}$ & & & 12.6 & 12.4 & 12.5 & 12.6 \\
\hline Relative risk & $0.99(0.91,1.07)$ & 0.770 & 1.00 Ref & $0.96(0.66,1.40)$ & $0.95(0.64,1.41)$ & $1.19(0.79,1.80)$ \\
\hline \multicolumn{7}{|l|}{ Meat alternatives } \\
\hline Median intake, svg/wk & & & 0.0 & 2.5 & 8.0 & 14.5 \\
\hline Median AOM, yr ${ }^{c}$ & & & 12.5 & $12.5(12.5)$ & $12.8(12.7)$ & 12.5 \\
\hline \multirow[t]{2}{*}{ Relative risk } & $1.01(0.90,1.13)$ & 0.838 & 1.00 Ref & $0.92(0.62,1.36)$ & $1.02(0.70,1.48)$ & $1.07(0.70,1.65)$ \\
\hline & & & Non-consumers & \multicolumn{2}{|c|}{ Low-moderate } & High \\
\hline \multicolumn{7}{|l|}{ Tofu/Traditional soy } \\
\hline Median intake, svg/wk & & & 0.0 & \multicolumn{2}{|c|}{1.0} & 4.8 \\
\hline Median AOM, yr ${ }^{c}$ & & & 12.5 & \multicolumn{2}{|c|}{12.6} & 12.4 \\
\hline Relative Risk & $0.90(0.70,1.16)$ & 0.401 & 1.00 Ref & \multicolumn{2}{|c|}{$0.93(0.68,1.26)$} & $1.00(0.72,1.40)$ \\
\hline \multicolumn{7}{|l|}{ Soy beverages } \\
\hline Median intake, svg/wk & & & 0.0 & \multicolumn{2}{|c|}{1.5} & 8.5 \\
\hline Median AOM, yr ${ }^{c}$ & & & 12.6 & \multicolumn{2}{|c|}{12.4} & 12.6 \\
\hline Relative Risk & $0.98(0.84,1.14)$ & 0.759 & 1.00 Ref & \multicolumn{2}{|c|}{$1.07(0.79,1.46)$} & $1.12(0.82,1.54)$ \\
\hline
\end{tabular}

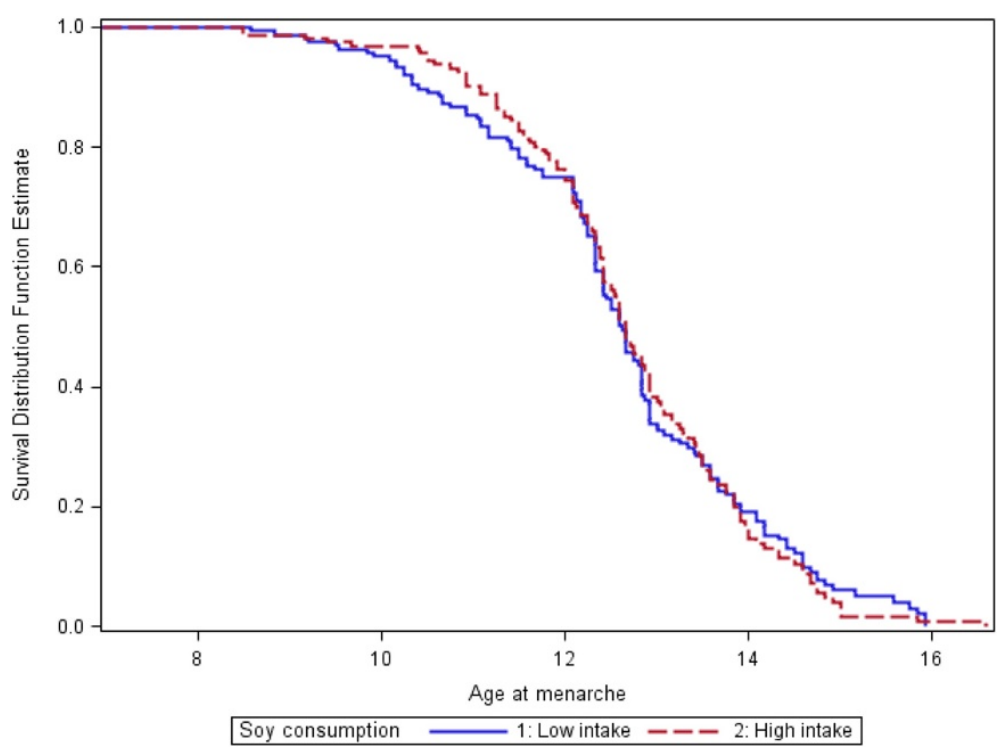

Figure 1 Age at menarche survival curves for low- and high-soy consumers. Legend: Kaplan-Meier survival curves are shown for both low and high consumers of soy. Median AOMs are 12.67 (low intake) vs. 12.58 (high intake) for B (plog rank test $=0.84$ ). Values are energy-adjusted. Age at menarche is in years. 
Table 4 Relative risks ( $95 \%$ confidence interval) ${ }^{a}$ for early onset (early AOM) or late onset (late AOM) ${ }^{b}$ of menarche according to levels of total soy and soy foods consumption

\begin{tabular}{|c|c|c|c|c|}
\hline & \multicolumn{4}{|c|}{ Level of Consumption ${ }^{c}$} \\
\hline & Quartile 1 & Quartile 2 & Quartile 3 & Quartile 4 \\
\hline \multicolumn{5}{|c|}{ Total soy intake } \\
\hline Early AOM & 1.00 Ref & $1.85(1.01,3.40)^{d}$ & $1.62(0.80,3.26)$ & $1.85(0.91,3.75)$ \\
\hline Late AOM & 1.00 Ref & $1.17(0.53,2.60)$ & $0.86(0.32,2.30)$ & $0.83(0.30,2.30)$ \\
\hline \multicolumn{5}{|c|}{ Meat alternatives } \\
\hline Early AOM & 1.00 Ref & $1.45(0.79,2.66)$ & $1.08(0.53,2.19)$ & $1.54(0.77,3.08)$ \\
\hline \multirow[t]{2}{*}{ Late AOM } & 1.00 Ref & $1.22(0.56,2.65)$ & $0.81(0.32,2.06)$ & $0.96(0.36,2.57)$ \\
\hline & \multicolumn{2}{|c|}{ Non-consumers } & Low-moderate & High \\
\hline \multicolumn{5}{|c|}{ Traditional soy } \\
\hline Early AOM & \multicolumn{2}{|c|}{ 1.00 Ref } & $1.30(0.81,2.08)$ & $1.39(0.81,2.38)$ \\
\hline Late AOM & \multicolumn{2}{|c|}{ 1.00 Ref } & $1.30(0.70,2.41)$ & $1.05(0.50,2.23)$ \\
\hline \multicolumn{5}{|l|}{ Soy beverages } \\
\hline Early AOM & \multicolumn{2}{|c|}{ 1.00 Ref } & $1.41(0.88,2.28)$ & $1.15(0.66,2.02)$ \\
\hline Late AOM & \multicolumn{2}{|c|}{ 1.00 Ref } & $0.95(0.52,1.74)$ & $0.70(0.31,1.57)$ \\
\hline
\end{tabular}

our study was 0.2 year ( 2.4 months), and 0.1 year $(\sim 1.2$ months) when adjusted for relevant covariates. A previous study reported a non-significant 4-month difference in AOM between those who were fed and those who were not fed soy formula during early infancy [22]. This larger difference was not significant, probably because of the small number of girls exposed to soy formula. On the other hand, our study involved a larger number of girls exposed and not exposed to soy foods; nevertheless, the AOM difference found in our study was smaller.

As expected, our study population has a wide range of soy consumption, from 0 intake to several servings per day (mean $[\mathrm{SD}]=12.9$ [14.4] svg/wk), with meat alternatives comprising more than half of the soy foods consumed. While there is a wide range in intake of tofu/traditional soy foods and soy beverages, these are less commonly consumed by this group compared to meat alternatives. About $20 \%$ drink soy beverages $\geq 1 \times /$ day while $\sim 23 \%$ eat tofu and traditional soy foods $\geq 3 \times /$ week whereas $\sim 54 \%$ eat meat alternatives $\geq 4 \times /$ wk.

We made the assumption that for our study population, it was better to assess current soy intake than to retrospectively assess soy intake before onset of menarche. Compared to adults, dietary assessment among children and adolescents is more prone to errors [34] and these errors can be compounded when recalling past consumption. Although it is presumed that dietary intake may change due to increased independence as children transition to adolescence, there is evidence to the contrary. In a study done on a diverse population of children ages 9-18 years, dietary intake patterns that were assessed 5 years apart have been found to be stable over time [35]. For decades, soy foods and beverages have been readily available in Adventist school cafeterias and local groceries near communities with an Adventist presence. Consumption of these foods among Adventists is not a recent fad but a lifestyle some families choose, or choose not to follow. In our web-based questionnaire, one section asked participants to report their intake of selected food items-which include tofu, meat alternatives, soymilk, and soy ice cream-when they were 8-10 years old relative to their current intake. Participants reported whether they never/rarely ate or ate these foods less than, the same, or more than their current intake. We found that current intake estimates were $61-80 \%$ in agreement with past consumption. This confirms the relative stability of soy foods intake in this population and a posteriori justifies our decision to ask participants to report their current intake. We believe this also relieved the undue burden of recalling childhood dietary intake and diminished measurement errors.

This report focused on exposure to soy as a food in its various forms. Previous soy-related studies have focused on one of its components, isoflavones. Aside from isoflavones, soy foods are also rich sources of high-quality plant proteins, omega- 6 and omega- 3 polyunsaturated fats, dietary fiber, and other phytochemicals. Some of these nutrients had been implicated in pubertal development: 
Higher vegetable protein intake during childhood had been found to be related to later onset of menarche $[27,36]$; dietary fiber was found to be an important factor in the hormonal maturation of pubertal girls [28] and associated with a delay in menarcheal age [29]; and, high dietary fat intake was found to be associated with early menarche [30]. Thus, several soy food compounds may synergistically impact the onset of menarche; that is, the effect of the food can be different from the effect of the sum of its components, and certainly, different from any single component. Consequently, a food approach has scientific merit, and may have direct practical applications for the consumer as well as the guided professional advice.

To our knowledge, this is the first study on the intake of soy foods during adolescence and AOM. Two previous studies looked at exposure to soy formula during infancy. Adgent et al. in the Avon Longitudinal Study of Parents and Children reported an earlier risk of menarche among girls who were fed soy formula in infancy; however, the 4-month median difference in AOM between those fed soy formula (149 mos or $12.4 \mathrm{yr}$ ) and those fed non-soy formula (153 mos or $12.8 \mathrm{yr}$ ) was not significant [22]. A retrospective cohort study that also looked at soy formula exposure during infancy did not find any difference between the AOM of soy-formula fed (mean = 12.6 years) and of cow milk formula-fed ( mean $=12.7$ years) participants [24]. The Dortmund Nutritional and Anthropometric Longitudinally Designed study assessed isoflavone exposure during childhood (before pubertal growth spurt). In a sub-sample of 119 white girls, no significant 4-month AOM difference was found between the highest and the lowest tertiles of isoflavone exposure [23].

A panel that examined US national data from 1940 to 1994 on puberty timing concluded that AOM has been decreasing [37]. At the same time, the use of soy-based formula and soy foods had increased in the US over the last few decades. Are these secular trends related? The mean AOM (12.5 years) of our high soy-consuming study population (born between 1994 and 2001) is the same as or slightly higher than the mean AOM of US girls (12.4 years) born 15 years earlier (1980-85) [1], which argues against a connection between these trends.

Evidence suggests that higher pre-pubertal BMI may influence the rate of pubertal development and earlier attainment of menarche [13]. BMI may be an intermediate variable in the causal path between diet and maturation $[14,38]$ but in our study, we did not have pre-pubertal BMI information so we used measured (current) BMI. We found BMI to be significantly associated with early menarche. We cannot discount the possibility that increase in body sizeand the corresponding increase in BMI-associated with pubertal changes is more prominent among those who had earlier menarche in our study, which may explain this association between BMI and early AOM.
One of the strengths of our study is that our female adolescent population has a wide range of soy intake, the majority of whom come from families that have relatively stable dietary patterns over the years $[39,40]$. The wide range of soy intake increases the power to find significant relationships, if they exist. Another strength is the use of an age-appropriate instrument for data collection with a web-based FFQ that assessed soy consumption with acceptable validity. Our study also has several weaknesses that should be considered when interpreting our findings. Although the extensive soy exposure may contribute to the ability to see significant differences between consumers and non-consumers, the sample size may not have been enough to see a significant 2-month difference in AOM. The cross-sectional design of the study precludes a firm temporal connection between soy intake and AOM. A prospective assessment of soy consumption in childhood may have provided a better dietary measurement than the current consumption that we used in our study. Additionally, the use of a web-based food frequency questionnaire is subject to the same inaccuracies in selfreporting intake as paper-based questionnaires, and thus, the purported error may have contributed to the null findings. The use of current BMI instead of pre-pubertal BMI is also a limitation due to the aforementioned reasons.

\section{Conclusions}

Our study findings indicate that soy consumption around the time of puberty is not associated with the AOM. The mean AOM of this population-which has a wide range of and relatively higher soy intake than the general U.S. population-is similar or slightly higher than the national norm. This suggests that the increased popularity of soy foods may not be related to the decreasing secular trend in menarcheal age among U.S. girls.

\section{Additional file}

Additional file 1: Food frequency questionnaire items.

\section{Competing interests}

MM regularly consults for companies that manufacture and/or sell soy foods. The other authors have no conflict of interest to declare.

\section{Authors' contributions}

JS conceived, designed and directed the study, and critically reviewed the manuscript; KO analyzed the data; MM critically reviewed and edited the manuscript; PP supervised the data collection and management for the Michigan side, and GSS designed the study with JS, supervised the data collection and management, and wrote the manuscript. All authors contributed to the editing and approval of the submitted manuscript.

\section{Acknowledgements}

Grant support for this study was from WhiteWave Foods, which took no part in any aspect of the study from conception to the preparation of the manuscript. We wish to thank the participants of this study, and to acknowledge Edward Bitok, Manijeh Nezami, Lynnley Huey, Tricia Norkunas, and Janice Hilton who, 
together with the rest of our research assistants, have diligently assisted in recruitment efforts and data collection.

\section{Author details}

'Department of Nutrition, Loma Linda University, 24951 North Circle Dr. Nichol Hall 1105, Loma Linda, CA 92350, USA. ${ }^{2}$ Department of Biostatistics and Epidemiology, School of Public Health, Loma Linda University, 24591 No. Circle Drive, Loma Linda, CA 92350, USA. ${ }^{3}$ School of Health Professions, Department of Public Health \& Wellness, Andrews University, 8475 University Boulevard - Marsh Hall, Berrien Springs, Ml 49104, USA. ${ }^{4}$ Nutrition Matters, Inc, 439 Calhoun Street, Port Townsend, WA 98368, USA.

Received: 9 December 2013 Accepted: 12 May 2014

Published: 3 June 2014

\section{References}

1. McDowell MA, Brody DJ, Hughes JP: Has age at menarche changed? Results from the National Health and Nutrition Examination Survey (NHANES) 1999-2004. J Adolesc Health 2007, 40:227-231.

2. Himes JH: Examining the evidence for recent secular changes in the timing of puberty in US children in light of increases in the prevalence of obesity. Mol Cell Endocrinol 2006, 254-255:13-21.

3. Aksglaede L, Sorensen K, Petersen JH, Skakkebaek NE, Juul A: Recent decline in age at breast development: the copenhagen puberty study. Pediatrics 2009, 123:e932-939.

4. Herman-Giddens ME: Recent data on pubertal milestones in United States children: the secular trend toward earlier development. Int J Androl 2006, 29:241-246. discussion 286-290.

5. Ruder EH, Dorgan JF, Kranz S, Kris-Etherton PM, Hartman TJ: Examining breast cancer growth and lifestyle risk factors: early life, childhood, and adolescence. Clin Breast Cancer 2008, 8:334-342

6. Barker DJ, Osmond C, Thornburg KL, Kajantie E, Eriksson JG: A possible link between the pubertal growth of girls and ovarian cancer in their daughters. Am J Hum Biol 2008, 20:659-662.

7. Collaborative Group on Hormonal Factors in Breast C: Menarche, menopause, and breast cancer risk: individual participant meta-analysis, including 118964 women with breast cancer from 117 epidemiological studies. Lancet Oncol 2012, 13:1141-1151.

8. Novotny R, Daida Y, Morimoto Y, Shepherd J, Maskarinec G: Puberty, body fat, and breast density in girls of several ethnic groups. Am J Human Biol 2011, 23:359-365.

9. Kaprio J, Rimpelä A, Winter T, Viken RJ, Rimpelä M, Rose RJ: Common genetic influences on BMl and age at menarche. Hum Biol 1995, 67:739-753.

10. Wolff MS, Teitelbaum SL, Pinney SM, Windham G, Liao L, Biro F, Kushi LH, Erdmann C, Hiatt RA, Rybak ME, Calafat AM, Breast Cancer and Environment Research Centers: Investigation of relationships between urinary biomarkers of phytoestrogens, phthalates, and phenols and pubertal stages in girls. Environ Health Perspect 2010, 118:1039-1046.

11. Buck Louis GM, Gray LE Jr, Marcus M, Ojeda SR, Pescovitz OH, Witchel SF, Sippell W, Abbott DH, Soto A, Tyl RW, Bourguignon JP, Skakkebaek NE, Swan SH, Golub MS, Wabitsch M, Toppari J, Euling SY: Environmental factors and puberty timing: expert panel research needs. Pediatrics 2008 121(Suppl 3):S192-207.

12. D'Aloisio AA, DeRoo LA, Baird DD, Weinberg CR, Sandler DP: Prenatal and infant exposures and age at menarche. Epidemiology 2013, 24:277-284.

13. Buyken AE, Karaolis-Danckert N, Remer T: Association of prepubertal body composition in healthy girls and boys with the timing of early and late pubertal markers. Am J Clin Nutr 2009, 89:221-230.

14. Demerath EW, Li J, Sun SS, Chumlea WC, Remsberg KE, Czerwinski SA, Towne B, Siervogel RM: Fifty-year trends in serial body mass index during adolescence in girls: the Fels Longitudinal Study. Am J Clin Nutr 2004, 80:441-446.

15. Rosenfield RL, Lipton RB, Drum ML: Thelarche, pubarche, and menarche attainment in children with normal and elevated body mass index. Pediatrics 2009, 123:84-88.

16. Biro FM, Lucky AW, Simbartl LA, Barton BA, Daniels SR, Striegel-Moore R, Kronsberg SS, Morrison JA: Pubertal maturation in girls and the relationship to anthropometric changes: pathways through puberty. J Pediatrics 2003, 142:643-646.

17. Remer T, Shi L, Buyken AE, Maser-Gluth C, Hartmann MF, Wudy SA: Prepubertal adrenarchal androgens and animal protein intake independently and differentially influence pubertal timing. J Clin Endocrinol Metab 2010, 95:3002-3009.

18. Rogers IS, Northstone K, Dunger DB, Cooper AR, Ness AR, Emmett PM: Diet throughout childhood and age at menarche in a contemporary cohort of British girls. Public Health Nutr 2010, 13:2052-2063.

19. Wiley AS: Milk intake and total dairy consumption: associations with early menarche in NHANES 1999-2004. PLoS One 2011, 6:e14685

20. Albertazzi P, Purdie D: The nature and utility of the phytoestrogens: a review of the evidence. Maturitas 2002, 42:173.

21. Kim J, Kim S, Huh K, Kim Y, Joung H, Park M: High serum isoflavone concentrations are associated with the risk of precocious puberty in Korean girls. Clin Endocrinol (Oxf) 2011, 75:831-835.

22. Adgent MA, Daniels JL, Rogan WJ, Adair L, Edwards LJ, Westreich D, Maisonet M, Marcus M: Early-life soy exposure and age at menarche. Paediatr Perinat Epidemiol 2012, 26:163-175.

23. Cheng G, Remer T, Prinz-Langenohl R, Blaszkewicz M, Degen GH, Buyken AE: Relation of isoflavones and fiber intake in childhood to the timing of puberty. Am J Clin Nutr 2010, 92:556-564.

24. Strom BL, Schinnar R, Ziegler EE, Barnhart KT, Sammel MD, Macones GA, Stallings VA, Drulis JM, Nelson SE, Hanson SA: Exposure to soy-based formula in infancy and endocrinological and reproductive outcomes in young adulthood. JAMA 2001, 286:807-814.

25. Gunther ALB, Karaolis-Danckert N, Kroke A, Remer T, Buyken AE: Dietary protein intake throughout childhood is associated with the timing of puberty. J Nutr 2010, 140:565-571.

26. Kissinger DG, Sanchez A: The association of dietary factors with the age of menarche. Nutr Res 1987, 7:471-479.

27. Berkey CS, Gardner JD, Frazier AL, Colditz GA: Relation of childhood diet and body size to menarche and adolescent growth in girls. Am J Epidemiol 2000, 152:446-452.

28. de Ridder CM, Thijssen JH, Van't Veer P, van Duuren R, Bruning PF, Zonderland ML, Erich WB: Dietary habits, sexual maturation, and plasma hormones in pubertal girls: a longitudinal study. Am J Clin Nutr 1991, 54:805-813.

29. Koo MM, Rohan TE, Jain M, McLaughlin JR, Corey PN: A cohort study of dietary fibre intake and menarche. Public Health Nutr 2002, 5:353-360.

30. Merzenich $\mathrm{H}$, Boeing $\mathrm{H}$, Wahrendorf J: Dietary fat and sports activity as determinants for age at menarche. Am J Epidemiol 1993, 138:217-224.

31. Biro FM, Huang B, Daniels SR, Lucky AW: Pubarche as well as thelarche may be a marker for the onset of puberty. J Pediatr Adolesc Gynecol 2008, 21:323-328.

32. Koprowski C, Coates RJ, Bernstein L: Ability of young women to recall past body size and age at menarche. Obes Res 2001, 9:478-485.

33. Salsberry PJ, Reagan PB, Pajer K: Growth differences by age of menarche in African American and white girls. Nurs Res 2009, 58:382-390.

34. Livingstone MBE, Robson PJ, Wallace JMW: Issues in dietary intake assessment of children and adolescents. Br J Nutr 2004, 92(Suppl 2):S213-222.

35. Cutler GJ, Flood A, Hannan P, Neumark-Sztainer D: Major patterns of dietary intake in adolescents and their stability over time. J Nutr 2009, 139:323-328.

36. Gunther ALB, Karaolis-Danckert N, Kroke A, Remer T, Buyken AE: Dietary protein intake throughout childhood is associated with the timing of puberty. J Nutr 2010, 140:565-571.

37. Euling SY, Herman-Giddens ME, Lee PA, Selevan SG, Juul A, Sorensen TI, Dunkel L, Himes JH, Teilmann G, Swan SH: Examination of US pubertytiming data from 1940 to 1994 for secular trends: panel findings. Pediatrics 2008, 121(Suppl 3):S172-191.

38. Ahmed ML, Ong KK, Dunger DB: Childhood obesity and the timing of puberty. Trends Endocrinol Metab 2009, 20:237-242.

39. Fraser GE, Lindsted KD, Knutsen SF, Beeson WL, Bennett H, Shavlik DJ: Validity of dietary recall over 20 years among California seventh-day adventists. Am J Epidemiol 1998, 148:810-818.

40. Lindsted KD, Kuzma JW: Long-term (24-year) recall reliability in cancer cases and controls using a 21 -item food frequency questionnaire. Nutr Cancer 1989, 12:135-149.

doi:10.1186/1475-2891-13-54

Cite this article as: Segovia-Siapco et al:: Is soy intake related to age at onset of menarche? A cross-sectional study among adolescents with a wide range of soy food consumption. Nutrition Journal 2014 13:54. 